\begin{tabular}{|c|c|c|}
\hline $\begin{array}{c}\text { Proceeding } \\
\text { SALATIGA }\end{array}$ & $\begin{array}{c}\text { Procember 2021 } \\
\text { 9-ISSN: 2827-9581 } \\
\text { Eebsite: http://conference.iainsalatiga.ac.id/index.php/iciegc }\end{array}$ & Hal. 129-136 \\
\hline
\end{tabular}

\title{
PELAKSANAAN PROGRAM BIMBINGAN DAN KONSELING BAGI ANAK BERKEBUTUHAN KHUSUS (ABK) DI SEKOLAH INKLUSI SMPN 17 MUKOMUKO
}

\author{
Yossi Hadiansyah $^{1}$, Musri Ali Gapur ${ }^{2}$, Tina Musyofah ${ }^{3}$, Triani Eka Pitri ${ }^{4}$, Rahmad Hidayat $^{5}$ \\ 1,2,3,4 IAIN Curup
}

\begin{tabular}{l}
\hline \hline Informasi Artikel \\
\hline Penulis Korespondensi: \\
Yossi Hadiansyah \\
Email: \\
yossihadiansyah01@gmail.com
\end{tabular}

\begin{abstract}
The purpose of this study is to describe the implementation of BK program for ABK in SMPN 17 Mukomuko inclusion school, emerging obstacles, and solutions that are carried out to overcome obstacles. The primary subjects in the study were guidance and counseling teachers. This type of research is field research. Data collection techniques through observation, interviews, documentation. From the results of the research obtained data, namely: the curriculum for ABK used in SMPN 17 Mukomuko is a modified 2013 Curriculum adjusting to the capabilities and needs of ABK based on the results of need assessment. The method used by BK teachers is generally the same as other normal students but the implementation is slightly different. Obstacles that arise in the implementation of the BK program for ABK in SMPN 17 Mukomuko inclusion school, namely: the provision of materials and media services as well as facilities and infrastructure. So that the solutions carried out to overcome the obstacles that arise are: helping to optimize the deliberation activities of BK teachers (MGBK), active in delegating BK teachers to participate in training / seminars, establishing cooperation with outstanding education teachers, adding BK personnel.
\end{abstract}

Keyword: Guidance and counseling; children with special needs; school of inclusion

\begin{tabular}{l}
\hline ABSTRAK \\
Tujuan dalam penelitian ini adalah untuk mendeskripsikan mengenai \\
pelaksanaan program BK bagi ABK di sekolah inklusi SMPN 17 \\
Mukomuko, hambatan yang muncul, serta solusi yang dilakukan \\
untuk mengatasi hambatan. Subjek primer dalam penelitian ini \\
adalah guru bimbingan dan konseling. Jenis penelitian ini merupakan \\
penelitian lapangan (field research). Teknik pengumpulan data \\
melalui observasi, wawancara, dokumentasi. Dari hasil penelitian \\
diperoleh data yaitu: kurikulum untuk ABK yang digunakan di \\
SMPN 17 Mukomuko adalah Kurikulum 2013 yang dimodifikasi \\
menyesuaikan dengan kemampuan dan kebutuhan ABK dengan \\
berpedoman pada hasil need asesment. Metode yang digunakan guru \\
BK pada umumnya sama dengan siswa normal lainnya akan tetapi \\
pada pelaksanaannya sedikit berbeda. Hambatan yang muncul dalam \\
pelaksanaan program BK bagi ABK di sekolah inklusi SMPN 17 \\
Mukomuko, yaitu penyediaan materi dan media layanan dan sarana \\
dan prasarana. Sehingga solusi yang dilakukan untuk mengatasi \\
hambatan yang muncul adalah: membantu mengoptimalkan kegiatan \\
musyawarah guru BK (MGBK), aktif dalam mendelegasikan guru
\end{tabular}


BK untuk mengikuti pelatihan/seminar, menjalin kerjasama dengan guru pendidikan luar biasa, menambah personil BK.

Kata kunci: Bimbingan dan konseling; anak berkebutuhan khusus; sekolah inklusi

\section{PENDAHULUAN}

Pendidikan yang bermutu merupakan salah satu hak yang harus diperoleh bagi setiap anak. Hadisumarto dalam Azwar menegaskan bahwa pendidikan yang mampu memfasilitasi berbagai perubahan adalah pendidikan yang merata, bermutu, dan relevan dengan kebutuhan masyarakatnya (Azwar, dkk., 2020). Dengan adanya sebuah akses pendidikan yang bermutu dan layak ini bukan hanya diperuntukkan untuk anak dengan kondisi sempurna (fisik maupun psikis) melainkan ditujukan untuk mereka yang mempunyai keterbatasan fisik ataupun psikis yang bisa disebut dengan istilah anak berkebutuhan khusus (ABK). Sesuai dengan label yang diberikan bahwa anak berkebutuhan khusus (ABK) seringkali tidak luput mendapatkan sebuah hambatan, kesulitan dan masalah saat beraktivitas di lingkungannya.

Heward dalam Oktari menyatakan anak berkebutuhan khusus (ABK) adalah anak dengan karakteristik khusus yang berbeda dengan anak pada umumnya tanpa selalu menunjukan pada ketidakmampuan mental, emosi, atau fisik. Kebutuhan dalam segi pendidikan yang sangat mendasar bagi anak berkebutuhan khusus (ABK) seringkali tidak diperoleh secara maksimal. Oleh karena itu dengan hadirnya pendidikan diharapkan dapat membantu anak berkebutuhan khusus (ABK) dalam pengembangan diri baik kepribadian maupun keterampilan hidupnya (Oktaria, dkk., 2020).

Pada era sekarang ini, kesempatan anak berkebutuhan khusus (ABK) untuk memperoleh atau mendapatkan pendidikan yang bermutu dan layak bertambah luas seiring dengan dicetuskannya yaitu sekolah inklusi. Pendidikan inklusi merupakan suatu sistem penyelenggaraan pendidikan yang memberikan kesempatan kepada semua peserta didik yang memiliki kelainan dan memiliki potensi kecerdasan dan/atau bakat istimewa untuk mengikuti pendidikan secara bersama-sama dengan peserta didik pada umumnya.

Disebutkan dalam pasal 32 ayat (1) yang berbunyi: "Pendidikan khusus merupakan pendidikan bagi peserta didik yang memiliki tingkat kesulitan dalam mengikuti proses pembelajaran karena kelainan fisik, emosional, mental, sosial, dan/atau memiliki kecerdasan dan bakat istimewa". Dari ketentuan-ketentuan ini jelas menyebutkan bahwa anak-anak luar biasa, istilah yang digunakan untuk anak berkebutuhan khusus berhak 
mendapat pendidikan yang bermutu seperti anak-anak pada umumnya, tanpa menganggap sebelah mata (Oktaria, dkk., 2020).

Atas dasar penjabaran di atas, pendidikan inklusif dihadirkan untuk memadukan antara anak normal dengan anak berkebutuhan khusus dalam satu kelas. Hal ini dilakukan bertujuan untuk memberikan kesempatan yang seluas-luasnya kepada semua peserta didik yang memiliki kelainan fisik, emosional, mental, sosial atau memiliki potensi kecerdasan dan bakat istimewa untuk memperoleh pendidikan yang bermutu sesuai dengan kebutuhan dan kemampuannya sehingga tidak muncul diskriminatif dalam dunia pendidikan.

Jika berbicara tentang pendidikan berarti tidak akan terlepas dari sekolah. Sekolah mempunyai peranan yang sangat vital dalam memberikan bekal bagi anak berkebutuhan khusus (ABK) agar ia mampu berkembang dan berhasil dalam hidup bermasyarakat. Anak berkebutuhan khusus (ABK) memerlukan penanganan khusus terutama dalam hal pendidikan. Salah satu cara yang dapat dilakukan oleh sekolah dalam rangka mengembangkan kepribadian dan keterampilan hidup anak berkebutuhan khusus (ABK) adalah dengan menyediakan guru BK di sekolah tersebut. Hal ini dikarenakan dalam usaha menyelenggarakan pelayanan BK, sebelumnya sudah adanya perencanaan yang matang. Perencanaan tersebut tertuang dalam program yang disusun secara sistematis (Fadila \& Hartini, 2015).

Sunaryo Kartadinata, dkk dalam penelitiannya menunjukkan bahwa program bimbingan dan konseling (BK) di sekolah akan berlangsung efektif dan efisien apabila didasarkan pada kebutuhan nyata dan kondisi objektif perkembangan peserta didik (Kurniawan, 2015). Selain itu dengan melalui implementasi bimbingan dan konseling di sekolah, disamping diharapkan mampu menunjang pencapaian tujuan pendidikan juga dapat membantu mengatasi hambatan belajar dan perkembangan yang dialaminya, sekaligus diharapkan mampu membantu upaya pengembangan totalitas kepribadian anak secara optimal sesuai dengan dimensi-dimensi kemanusiaannya menuju kebahagiaan hidup sesuai dengan nilai-nilai yang dianutnya (Aisyah, 2014). Oleh sebab itu dengan adanya Guru BK melalui program dan layanan bimbingan dan konseling dapat menjadi alternatif yang tepat dalam membantu untuk mengembangkan potensi yang ada dalam diri anak berkebutuhan khusus (ABK) supaya berkembang secara optimal.

Sekolah Menengah Pertama (SMP) Negeri 17 Mukomuko merupakan salah satu sekolah yang menyelenggarakan pendidikan inklusi bagi anak berkebutuhan khusus (ABK). Siswa ABK yang berada di SMPN 17 Mukomuko terdiri dari siswa yang menderita autis 
dan siswa dengan gangguan lamban belajar (slow learner). Berdasarkan uraian di atas, maka peneliti tertarik untuk meneliti bagaimana pelaksanaan program BK bagi anak berkebutuhan khusus (ABK) di sekolah inklusi SMPN 17 Mukomuko. Tujuan dalam penelitian ini adalah untuk mendeskripsikan: 1) Pelaksanaan program BK bagi ABK di sekolah inklusi SMPN SMPN 17 Mukomuko, 2) Hambatan yang muncul dalam pelaksanaan program BK bagi ABK di sekolah inklusi SMPN 17 Mukomuko, dan 3) Solusi yang digunakan untuk mengatasi hambatan dalam pelaksanaan program BK bagi ABK di sekolah inklusi SMPN 17 Mukomuko.

\section{METODE}

Jenis penelitian ini adalah penelitian lapangan (field research) yaitu penelitian yang objeknya mengenai gejala-gejala atau peristiwa-peristiwa yang terjadi pada kelompok masyarakat. Sehingga penelitian ini juga bisa disebut penelitian kasus atau studi kasus (case study) dengan pendekatan deskriptif (Arikunto, 2013). Lokasi penelitian di SMPN 17 Mukomuko. Pemilihan sekolah ini sebagai latar penelitian dikarenakan sekolah ini merupakan sekolah rintisan untuk pendidikan inklusi atau salah satu penyelenggara sekolah inklusi serta jumlah anak berkebutuhan khusus (ABK) di sekolah ini cukup banyak dan juga beragam. Subjek penelitian dipilih berdasarkan kriteria kesesuaian dengan tujuan penelitian (purposive sampling) agar menghasilkan data yang akurat. Dalam penelitian ini subjek penelitian terdiri dari: guru bimbingan dan konseling sebagai subjek primer serta kepala sekolah, wali kelas, dan koordinator pengelolaan dan inklusi merupakan subjek pelengkap atau penunjang. Teknik pengumpulan data menggunakan observasi, wawancara/interview, dan dokumentasi.

\section{HASIL DAN BAHASAN}

\section{Pelaksanaan program BK bagi ABK di sekolah inklusi SMPN 17 Mukomuko}

Berdasarkan hasil wawancara dengan guru BK di SMPN 17 Mukomuko dapat diketahui bahwa siswa berkebutuhan khusus di SMPN 17 Mukomuko ini terdiri dari anak dengan lamban belajar (slow learner) dan anak autis. Dalam hal kegiatan penerimaan siswa antara anak berkebutuhan khusus (ABK) dengan siswa normal lainnya dilaksanakan secara bersamaan tanpa ada perbedaan. Akan tetapi dalam kegiatan need assesment (pengukuran kebutuhan siswa) sebagai dasar membuat program, untuk anak berkebutuhan khusus (ABK) ditekankan untuk mengetahui kemampuan, kekurangan dan kelebihan, hal-hal yang disukai/tidak, boleh/tidak boleh (pantangan atau alergi khusus yang diderita), serta 
menyangkut riwayat kesehatan dari anak berkebutuhan khusus (ABK). Bertolak dari data tersebut, guru BK kemudian mengolah dan menganalisis karakteristik dari anak berkebutuhan khusus (ABK) sekaligus membuat program layanan yang sesuai kebutuhan anak.

Kurikulum yang digunakan di SMPN 17 Mukomuko adalah Kurikulum 2013. Akan tetapi, dalam keperluan anak berkebutuhan khusus (ABK) disesuaikan (dimodifikasi) dengan kemampuan dan kebutuhan ABK dengan berpatokan dari hasil need asessment. Berkenaan dengan jadwal pelaksanaan BK untuk anak berkebutuhan khusus (ABK) sesuai dengan jadwal yang telah disusun oleh sekolah. Supaya siswa ABK dapat menguasi materi yang diberikan maka materi yang diberikan kepada siswa ABK telah disesuaikan dengan kebutuhan masing-masing siswa. Artinya bahwa jika guru BK merasa materi yang ingin disampaikan terlalu berat, maka guru perlu menyederhanakan materi atau mengganti materi yang lain. Dalam pelaksanaan layanan BK seperti layanan klasikal untuk siswa yang slow learner, pelaksanaan layanan BK bisa dilakukan bersama siswa normal lainnya. Sedangkan untuk siswa dengan autis pelaksanaan pemberian layanan dilaksanakan di ruang BK agar lebih efektif. Sedangkan untuk layanan lainnya yang bersifat pribadi atau individu dilakukan secara insendental menyesuaikan dengan apa yang dibutuhkan oleh anak berkebutuhan khusus (ABK) yang ada di sekolah.

Menurut pandangan peneliti dalam hal penggunaan kurikulum 2013 dalam sistem pembelajaran untuk siswa bagi anak berkebutuhan khusus (ABK) sudah dilaksanakan dengan cukup baik. Hal ini bisa dilihat bagaimana kurikulum tersebut telah dimodifikasi menyesuaikan dengan kebutuhan anak berkebutuhan khusus (ABK) yang ada di sekolah. Selain itu, dalam kegiatan need asessment (pengukuran kebutuhan siswa) sebagai dasar pembuatan program BK serta metode atau cara dalam pelaksanaan bimbingan dan konseling untuk siswa anak berkebutuhan khusus (ABK) juga telah disesuaikan dengan tingkat kemampuan dan kecerdasan yang dimiliki oleh siswa ABK tersebut.

\section{Hambatan yang muncul dalam pelaksanaan program BK bagi ABK di sekolah inklusi SMPN 17 Mukomuko}

Hambatan yang muncul dalam pelaksanaan program BK bagi anak berkebutuhan khusus (ABK) yaitu sebagai berikut:

1. Penyediaan materi dan media layanan 
Seperti yang diketahui bahwa setiap anak berkebutuhan khusus (ABK) mempunyai kelemahan dan kelebihan serta karakterisktik yang berbeda-beda antara satu dengan yang lainnya. Hal ini membuat guru BK harus sebisa mungkin menyesuaikan materi layanan agar dapat mencakup setiap kebutuhan anak yang berbeda-beda. Selain itu juga guru BK seringkali mengalami kesulitan dalam membuat media yang tepat bagi anak berkebutuhan khusus (ABK). Karena tidak jarang setiap akan memberikan layanan BK, guru BK harus menyediakan bermacam-macam media yang menarik dan tidak terkesan membosankan serta mampu mempermudah dalam menyampaikan maksud dari isi materi atau layanan yang diberikan. Dalam hal ini guru BK masih belum bisa mengoptimalkan hal-hal tersebut.

\section{Sarana dan Prasarana}

Segi sarana dan prasarana di SMPN 17 Mukomuko sudah cukup mempenghuni. Akan tetapi dalam hal instrumen-instrumen yang digunakan guru BK dalam kegiatan need assesment sebagai dasar pembuatan program masih kurang mendukung dan terkesan apa adanya saja. Selain itu personel guru BK di SMPN 17 Mukomuko hanya berjumlah ada dua orang. Hal ini dirasakan kurang karena di sekolah tersebut dalam pelaksanaannya guru BK harus terbagi fokusnya antara anak berkebutuhan khusus (ABK) dengan siswa normal lainnya.

Menurut asumsi peneliti berdasarkan data didapatkan hambatan yang muncul dalam pelaksanaan program BK bagi ABK di sekolah inklusi SMPN 17 Mukomuko ini terbagi menjadi dua faktor yaitu faktor internal dan eksternal. Hambatan yang muncul dari faktor internal berdasarkan guru BK itu sendiri. Hal itu dapat diketahui dari bagaimana kurang optimalnya guru BK dalam menyediakan materi dan media yang sesuai dengan kebutuhan siswa ABK. Sedangkan untuk hambatan dari faktor ekternal merupakan hambatan yang muncul di luar dari guru BK. Dalam faktor ekternal yang muncul dalam pelaksanaan program BK bagi anak berkebutuhan khusus (ABK) yaitu kurangnya instrumen penunjang untuk kegiatan need asessment sebagai acuan guru BK untuk membuat program yang mampu mengakomodir kebutuhan-kebutuhan dari anak berkebutuhan khusus (ABK). Selain itu jumlah guru BK yang terbatas mengakibatkan dalam pelaksanaan layanan, guru BK sering mengalami kualahan dan kesulitan dalam memanajemen waktu karna mengingat fokus dari guru BK bukan hanya untuk anak berkebutuhan khusus (ABK) saja melainkan juga siswa normal lainnya. 


\section{Solusi yang dilakukan untuk mengatasi hambatan yang muncul dalam pelaksanaan program BK bagi ABK di sekolah inklusi SMPN 17 Mukomuko}

Beberapa solusi yang dilaksanakan oleh pihak sekolah untuk mengatasi hambatan yang dihadapi adalah sebagai berikut:

1. Membantu mengoptimalkan kegiatan musyawarah guru BK (MGBK) yang rutin dilakukan oleh guru BK di sekolah yang dapat dimanfaatkan oleh guru BK untuk bertukar pikiran atau mendapatkan informasi/pengetahuan yang baru berkenaan bagaimana cara menghadapi dan membantu siswa berkebutuhan khusus

2. Aktif dalam mendelegasikan guru BK untuk mengikuti pelatihan/seminar yang berhubungan dengan pelaksanaan bimbingan dan konseling dan anak berkebutuhan khusus

3. Menjalin kerjasama dengan guru pendidikan luar biasa terkait penanganan dan pemberian terapi kepada anak berkebutuhan khusus

4. Pihak sekolah akan menambah personil BK jika memungkinkan untuk dilakukan

Bertumpu pada solusi di atas maka peneliti dapat menganalisa bahwa sekolah sudah mempunyai solusi atau alternatif pemecahan yang tepat. Karena dengan kegiatan seperti sekolah membantu atau mendukung mengoptimalkan kegiatan musyawarah guru BK (MGBK) dengan cara meminta guru BK yang ada di sekolah untuk aktif berpartisipasi dalam kegiatan tersebut, aktif dalam mendelegasikan guru BK untuk mengikuti pelatihan/seminar, menjalin kerjasama dengan guru pendidikan luar biasa, pihak sekolah akan menambah personil BK jika memungkinkan untuk dilakukan. Solusi-solusi yang dilakukan oleh pihak sekolah semata-mata untuk memaksimalkan kinerja guru BK agar mampu menghadapi hambatan yang muncul. Oleh karenanya untuk membentuk sebuah sistem pendidikan yang tepat bagi siswa ABK memang harus dipersiapkan dengan sebaik baik mungkin.

\section{KESIMPULAN}

Berdasarkan hasil penelitian dan pembahasan secara keseluruhan tentang pelaksanaan program bimbingan dan konseling bagi anak berkebutuhan khusus (ABK) di sekolah inklusi SMPN 17 Mukomuko, maka dapat ditarik kesimpulan sebagai berikut: 1) Kurikulum yang diterapkan di SMPN 17 Mukomuko adalah kurikulum 2013. Hanya saja, untuk keperluan siswa berkebutuhan khusus (ABK) dilakukan modifikasi sesuai dengan kemampuan dan kebutuhan ABK dengan berpatokan dari hasil need asesment. Materi yang diberikan kepada 
siswa $\mathrm{ABK}$ telah disesuaikan dengan kebutuhan masing-masing siswa; 2) Hambatan yang muncul dalam pelaksanaan program BK bagi ABK di sekolah inklusi SMPN 17 Mukomuko mencakup: Penyediaan materi dan media layanan dan Sarana/Prasarana; dan 3) Solusi yang dilakukan untuk mengatasi hambatan yang muncul adalah sebagai berikut: a) Membantu mengoptimalkan kegiatan musyawarah guru BK (MGBK) yang rutin dilakukan oleh guru BK, b) Aktif dalam mendelegasikan guru BK untuk mengikuti pelatihan/seminar yang berhubungan dengan pelaksanaan bimbingan dan konseling dan anak berkebutuhan khusus, c) Menjalin kerjasama dengan guru pendidikan luar biasa terkait penanganan dan pemberian terapi kepada anak berkebutuhan khusus, dan d) Pihak sekolah akan menambah personil BK jika memungkinkan untuk dilakukan.

\section{DAFTAR RUJUKAN}

Aisyah, U. (2014). Strategi Layanan Bimbingan Dan Konseling Bagi Siswa Tunanetra Mts Yaketunis Yogyakarta. Educatio: Jurnal Ilmu Kependidikan, 9(2), 223-247.

Arikunto, S. (2013). Prosedur Penelitian Suatu Pendekatan Praktek. Jakarta: Rineka Cipta. Azwar, B., Syahindra , W., \& Widyastuti, R. (2020). Evaluasi Praktik Pengalaman Lapangan Terhadap Dampak Penyelesaian Skripsi Mahasiswa IAIN Curup. TADBIR: Jurnal Studi Manajemen Pendidikan, 4(2), 216-232.

Fadila, \& Hartini. (2015). Analisis Kebutuhan Mahasiswa Jurusan Tarbiyah Terhadap Pelayanan Konseling. Jurnal Prosiding, Batusangkar, 1(1), 190-198.

Kurniawan, L. (2015). Pengembangan Program Layanan Bimbingan Dan Koseling Komprehensif Di SMA. Jurnal Psikologi Pendidikan Dan Konseling, 1(1), 1-8.

Oktari, W., Harmi, H., \& Wanto, D. (2020). Strategi Guru Dalam Pembelajaran PAI Pada Anak Berkebutuhan Khusus. Ta'dibuna: Jurnal Pendidikan Agama Islam, 2(2), 1328. 